\title{
The complete chloroplast genome sequence of Asian Palmyra palm (Borassus flabellifer)
}

\author{
Arpakorn Sakulsathaporn ${ }^{1,2}$, Passorn Wonnapinij ${ }^{3,4}$, Supachai Vuttipongchaikij, ${ }^{3,4,5^{*}}$ \\ and Somsak Apisitwanich 1,2,3,4,5,6*
}

\begin{abstract}
Objective: Borassus flabellifer or Asian Palmyra palm is widely distributed in South and Southeast Asia and is horticultural and economic importance for its fruit and palm sugar production. However, its population is in rapid decline, and only a few genetic data are available. We sequenced the complete chloroplast (cp) genome of B. flabellifer to provide its genetic data for further utilization.

Results: The cp genome was obtained by Illumina sequencing and manual gap fillings providing 160,021 bp in length containing a pair of inverted repeats (IRs) with 27,256 bp. These IRs divide the genome into a large single copy region $87,444 \mathrm{bp}$ and a small single copy region 18,065 bp. In total, 113 unique genes, 134 SSRs and 47 large repeats were identified. This is the first complete cp genome reported in the genus Borassus. A comparative analysis among members of the Borasseae tribe revealed that the B. flabellifer cp genome is, so far, the largest and the cp genomes of this tribe have a similar structure, gene number and gene arrangement. A phylogenetic tree reconstructed based on 74 protein-coding genes from 70 monocots demonstrates short branch lengths indicating slow evolutionary rates of cp genomes in family Arecaceae.
\end{abstract}

Keywords: Arecaceae, Borasseae, Commelinids, Phylogeny, Plastid, Tandem repeats

\section{Introduction}

Borassus flabellifer or Asian palmary palm (family Arecaceae, subfamily Coryphoideae, Borasseae tribe) is a massive dioecious monocot plant with its single stem reaching $30 \mathrm{~m}$ in height and large fan-shaped leaves spanning 1-3 $\mathrm{m}$ in diameter [1]. Six species are present in the Borasseae tribe including $B$. aethiopum [2], $B$. akeassii [3], B. sambiranensis [4] and B. madagascariensis [5], which are distributed in Africa, B. heineanus [6] found in New Guinea and B. flabellifer, which is solely found in Asia [1]. B. flabellifer is widespread in the South and Southeast Asia and is of horticultural and economic importance. The fruit is widely consumed, and the

\footnotetext{
*Correspondence: fsciscv@ku.ac.th; fscissa@ku.ac.th

${ }^{3}$ Department of Genetics, Faculty of Science, Kasetsart University, 50

Ngarm Wong Wan Road, Chattuchak, Bangkok 10900, Thailand

Full list of author information is available at the end of the article
}

flower sap has been used for palm sugar production for hundreds of years [7]. B. flabellifer is currently in rapid decline due to following reasons. First, it grows extremely slow requiring $12-20$ years to reach maturity and produce its first inflorescence [8]. Second, urbanization and agricultural development has eliminated a large number of the wild population [9]. Third, it reproduces via cross pollination, but there is currently no reliable mean for sex determination prior its first flowers [10]. Fourth, a clonal propagation method for this species is not well established. With these reasons, conservation and breeding programs of $B$. flabellifer is urgently needed, and genetic data are required for supporting the programs.

To date, genetic data of B. flabellifer are limited. A number of DNA markers including RAPD [11], ISSR [12], EST-SR and gSSR [13, 14] have been developed for studying the population in south and southeast Asia and demonstrated its low genetic diversity. However, more 
sequence data are still needed for detailed studies on genetic diversity and evolution. In particular, the chloroplast (cp) genome sequence would provide both species specific and population specific makers for studying $B$. flabellifer. Here, we report the complete cp genome sequence of $B$. flabellifer obtained by using both nextgeneration sequencing and manual gap fillings. The $\mathrm{cp}$ genome structure, characteristic and gene organization are described. Repetitive sequences were identified. Comparative genome analysis was performed to understand the evolutionary relationship among the Borasseae tribe.

\section{Main text}

\section{The complete $\mathrm{cp}$ genome sequence of $B$. flabellifer}

Because B. flabellifer leaf materials are very hard and a direct isolation of cpDNA with high purity is often difficult to obtain, chloroplast was firstly isolated using a modified protocol from Triboush et al. [15] and purified using a modified sucrose gradient method from Sandbrink et al. [16] (Additional file 1: Figure S1). The third leaf from the top (a fully expanded leaf with dark green and no more than 6-month-old) was collected and stored at $4{ }^{\circ} \mathrm{C}$ for 7 days to reduce accumulated starch before use. CpDNA was then isolated from the purified chloroplast using DNeasy Plant Mini Kit (Qiagen), and EcoRI restriction digests were used for verifying the purity of the cpDNA. Illumina Hiseq 2000 system generated 7,695,267 pair-end reads with an approximately $100 \mathrm{bp}$ average read length. After filtering and eliminating low quality reads and contaminants using FastQC [17] and Trimmomatic [18], a total of $1,539,053,400 \mathrm{bp}$ was obtained. A sliding window size of 4 with an average of Phred score $\geq 20$ and removal of $5^{\prime}$ and $3^{\prime}$ ends with Phred score $\leq 3$ were used as the trimming criteria. By mapping to the cp genome of C. nucifera (NC_022417) [19] using SOAPec v2.03, the reads provided an average of $100 \times$ sequencing depth coverage, and eight contigs covering $92 \%$ of the entire cp genome was obtained. Specific PCR amplification and sequencing were performed to fill the missing gaps. The genome map was then drawn by GenomeVx [20].

The circular double-stranded DNA of the complete $B$. flabellifer cp genome is 160,021 bp in length (Fig. 1, GenBank Accession Number: KP_901247). It has a typical quadripartite structure composing of a pair of inverted repeat (IR) regions (27,256 bp each), a large single-copy (LCS) region $(87,444 \mathrm{bp})$ and a small single-copy (SSC) region $(18,065 \mathrm{bp})$. The overall GC content is $37.23 \%$. Genome annotation using DOGMA [21] and CpGAVAS [22] with Phoenix dactylifea [23] as a reference and tRNAs prediction using tRNA-ScanSE [24] provided that the $\mathrm{cp}$ genome contains 113 unique genes: 79 protein-coding genes, 30 tRNA genes, and four rRNA genes (Additional file 2: Table S1). All of the four rRNA genes (rrn4.5, rrn5, rrn16 and rrn23), seven proteincoding genes (rps19, rpl2, rpl23, ndhB, rps7, $y c f 1$ and $y c f$ $2)$, two pseudogenes $(y c f 15, y c f 68)$ and eight tRNA genes (trnH-GUG, trnI-CAU, trnL-CAA, trnV-GAC, trnIGAU, trnA-UGC, trnR-ACG, trnN-GUU) are located within the IR regions. The LSC region contains 82 protein-coding genes and 21 tRNA genes, while the SSC region contains 13 protein-coding genes and one tRNA gene. The rRNA, tRNA and protein-coding genes cover 9040 bp (5.65\%), 2873 bp (1.80\%) and 79,368 bp (49.6\%), respectively, of the complete genome.

Among 113 unique genes, there are 18 intron-containing genes (Additional file 2: Table S1): 16 genes with a single intron and two genes with two introns. Among these, trnK-UUU (3216 bp) contains the largest intron, in which matK gene (1551 bp) is located. Four pairs of overlapped genes with different ranges of overlapped bases were observed including $a t p E$ and $a t p B$ (four overlapped bases), $n d h \mathrm{~K}$ and $n d h \mathrm{C}$ (10 overlapped bases), $p s b \mathrm{D}$ and $p s b \mathrm{C}$ (53 overlapped bases) and $n d h \mathrm{~F}$ and pseudo-ycf1 (60 overlapped bases). The frequency of codons in this cp genome was calculated from the exons of protein-coding genes (pseudogenes were omitted) using Maga 6 (Additional file 2: Table S2). The observed initiation codons are AUG, GUG and ACG. The GUG initiation codon was found to be specific for rps 19 and $n d h \mathrm{D}$, while the ACG initiation codon was found only for $r p l 2$.

\section{Simple sequence repeats (SSRs) and repetitive sequences}

Identifications of SSRs and repetitive sequences using by REPuter program (under a cut off $\mathrm{n} \geq 10$ with $100 \%$ sequence identities) [25] and GMATo v1.2 [26] showed that the cp genome contains, in total, 134 SSR loci and 47 large repeat loci (Additional file 2: Tables S3 and S4). Among the 134 SSRs, 98 and 20 loci are homopolymers and dipolymers, respectively. And, 108 loci are located in intergenic spacer (IGS) regions, while 26 loci are located in the protein-coding genes including $\operatorname{cem} \mathrm{A}$, mat $\mathrm{K}$, $n d h \mathrm{D}, n d h \mathrm{~F}, n d h \mathrm{H}, r p o \mathrm{C} 2, r p s 14, r p s 19, r p s 4$ and $y c f 1$. Neither pentapolymer nor hexapolymer was observed in the protein-coding regions. All 47 large repeat sequences contain four non-tandem direct repeats, six inverted repeats and 37 tandem repeats. The sizes of the repeating unit were in the range of 11-39 bp (Additional file 2: Table S4). Noting that most of the large repeats are located in the IGSs inside the single-copy regions, especially in the large single-copy region. Only eight repeats including one direct repeat and seven tandem repeats are located in the coding sequence of three protein-coding genes: $r p o C 2, y c f 1$, and $y c f 2$. 


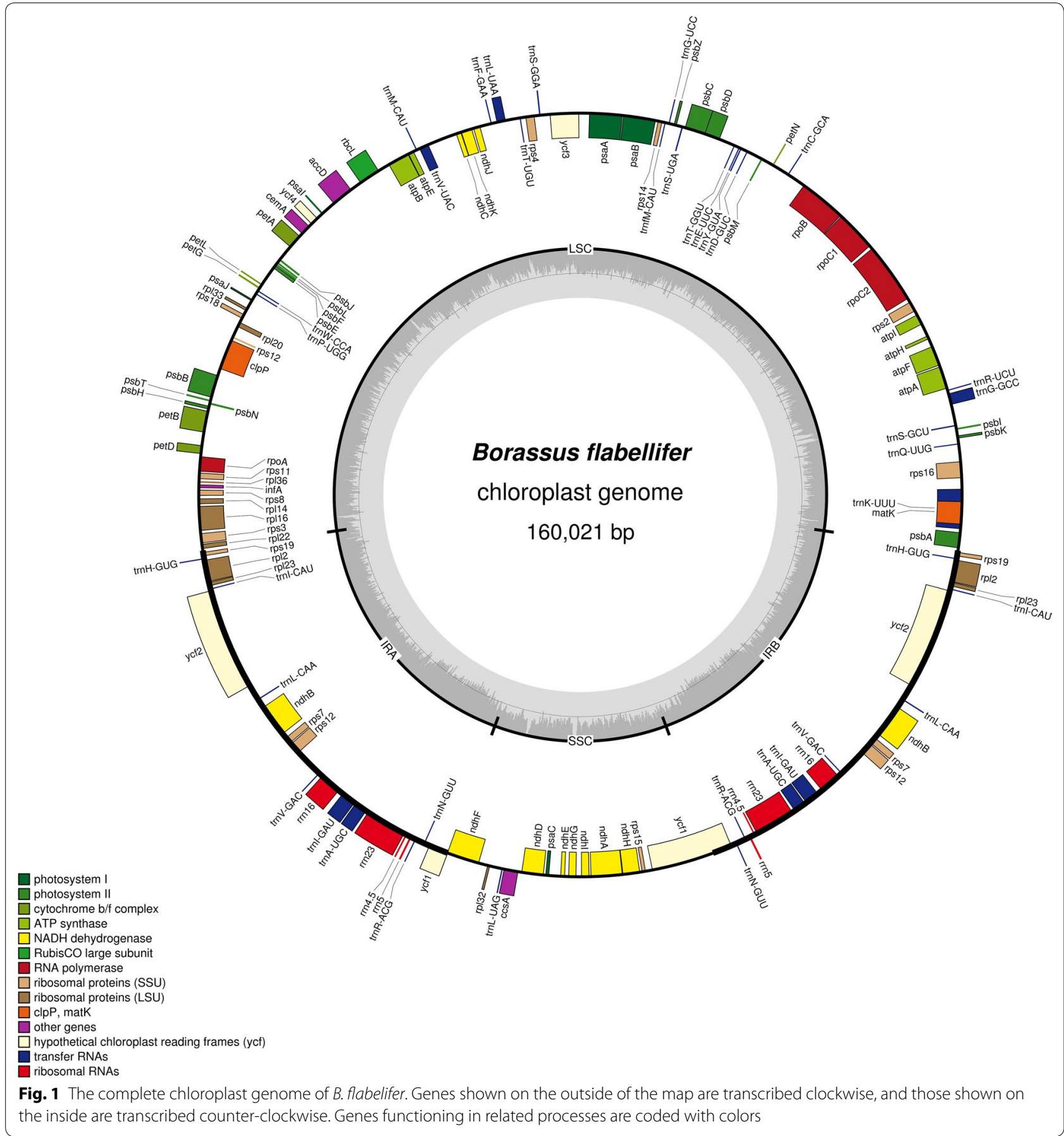

\section{Comparative analysis of the plastid genomes} among the Borasseae tribe and phylogenetic analysis among monocots

The cp genomes of 4 species including B. flabellifer, Bismarckia nobilis (NC_020366.1) [27], Borassodendron machadonis (NC_029969.1) [27] and Lodoicea maldivica (NC_029960.1) [27], which are members of Borasseae tribe are in the range between 158,144 and $160,021 \mathrm{bp}$
(Additional file 2: Table S5). The differences in the $\mathrm{cp}$ genome sizes are due to the lengths of the LSC, SSC and IR regions. The cp genome of $B$. flabellifer is, so far, the largest among the Borasseae tribe with the longest LSC and SSC regions. These long LSC and SSC regions contain the same number of genes as in the other three $\mathrm{cP}$ genomes. Comparative analysis using mVISTA [28] showed that the four cp genomes are highly 
similar (Fig. 2). Among the four sequence regions, both IR regions are more conserved than the LSC and SSC, which contain several variable regions in the intergenic regions such as between ndhF-rpl32, trnG-trnR and rpl32-trnL. Besides, there are 11 small variable regions inside the coding regions of accD, ccsA, mat $\mathrm{K}$, ndhA, $n d h D, n d h F, r b c l, r p l 16, r p o C 2, r p s 16$ and $y c f 1$. Noting that $y c f 1$ and rpoC2 also carry both SSRs and large repeats.

A phylogenetic tree based on the maximum likelihood method were reconstructed with raxmlGUI [29] using 74 protein-coding genes from 70 monocot species. The evolutionary relationship among monocots is presented with high bootstrap supports (Fig. 3). Previously, phylogenetic relationship among subfamilies, families and orders of the Commelinid clade using cp genomes has been described [27, 30,31], and our result is consistent with these reports. Tribes within subfamily Coryphoideae was previously divided into two major clades: [(Phoeniceae, Livistoneae)(Sabaleae, Cryosophileae)) and (Chuniophoeniceae (Caryota (Coryphoideae, Borasseae))] [27], and, here, we provide a confirmation for this clustering with $100 \%$ bootstrap supports. The phylogenetic tree showed that B. machadoris is closely related to B. flabellifer as supported by $100 \%$ bootstrap replicates. Furthermore, our phylogenetic tree showed that the branch lengths of all members of the family Arecaceae are short, suggesting slow evolutionary rates of the cp genomes in this family.

\section{Limitations}

The complete cp genome of B. flabellifer reported here provides a valuable resource for genetic analysis of this and related palm species. A number of SSRs, repetitive

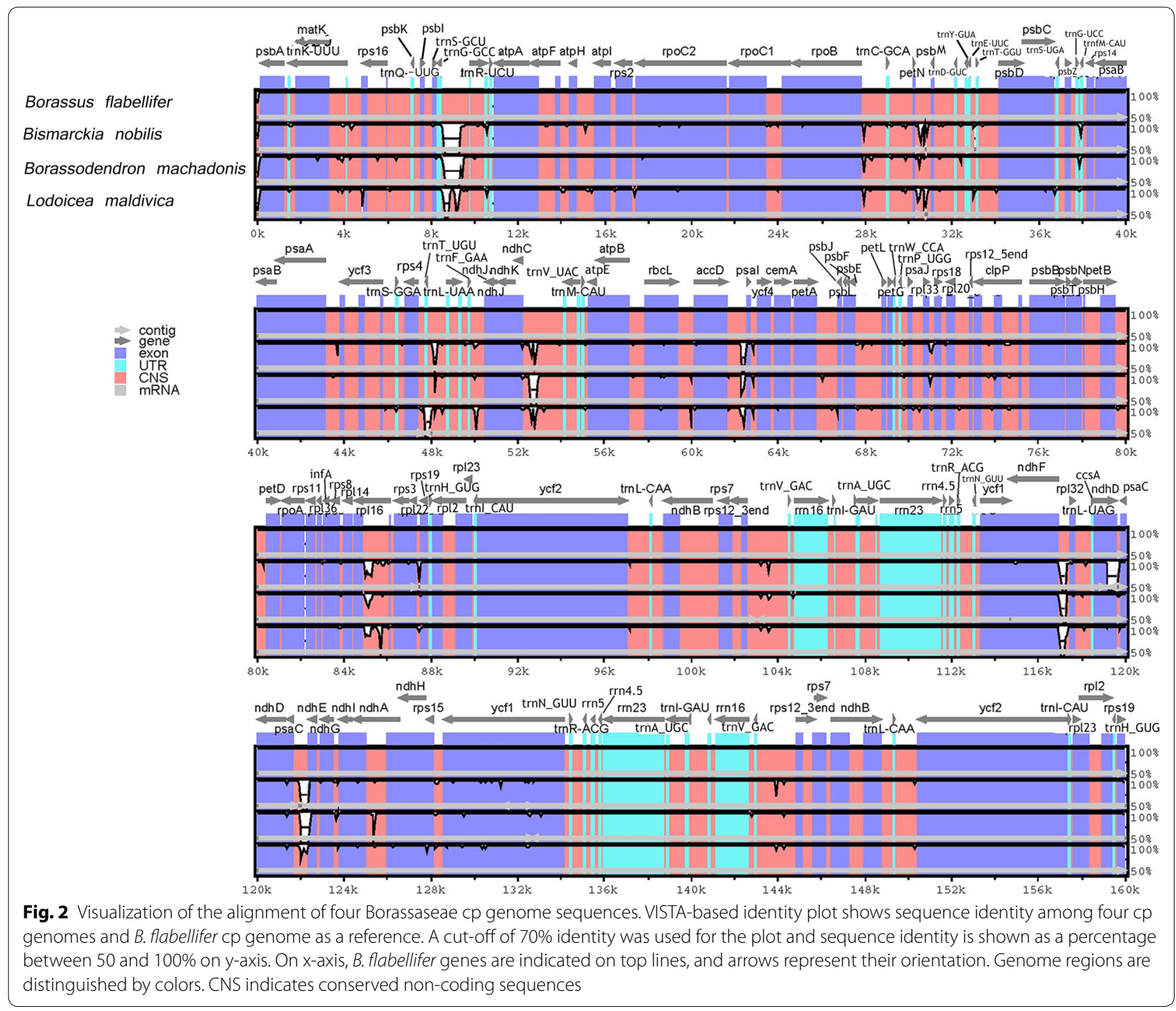




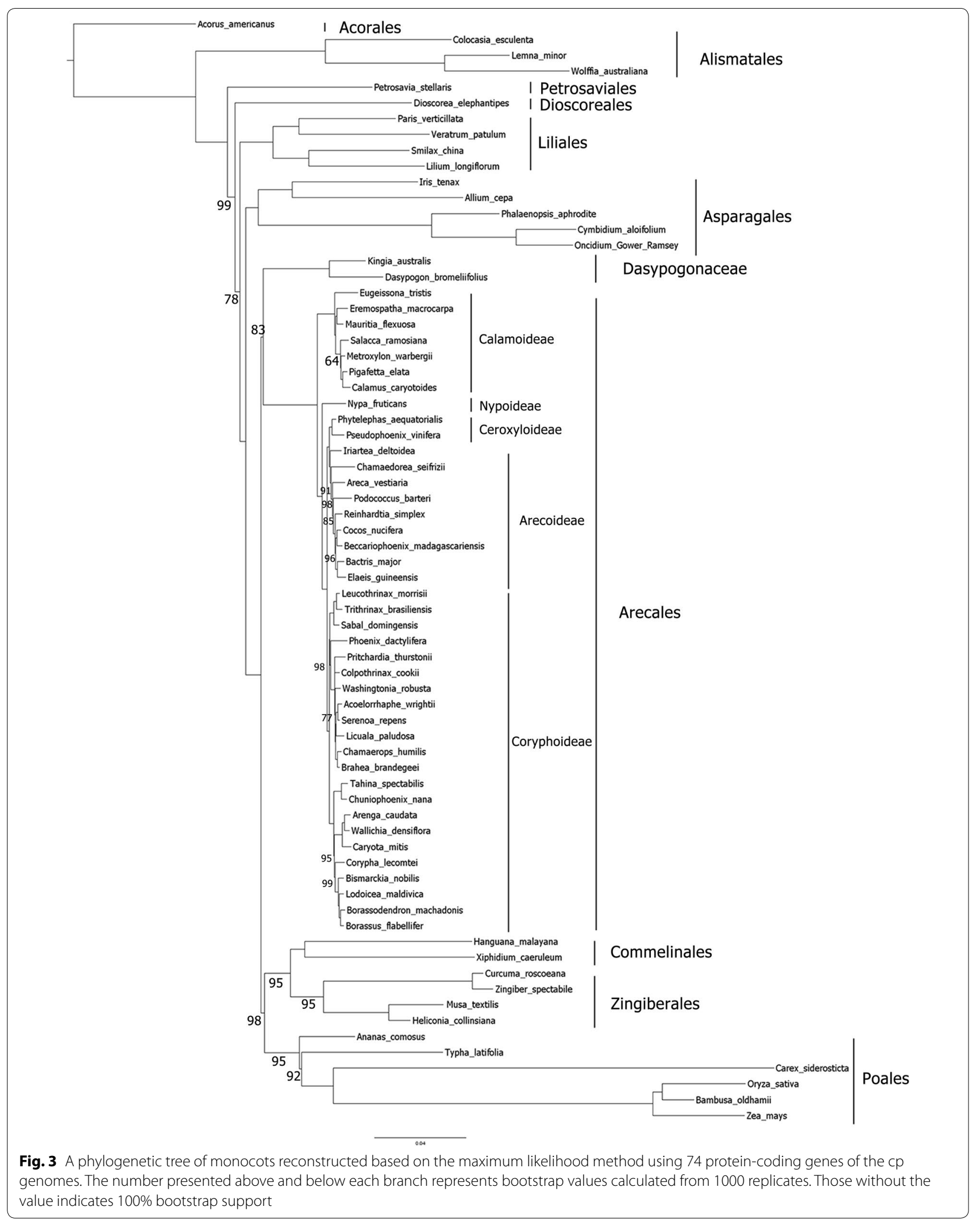


sequences and highly variable regions identified here would provide useful markers for studying the genetic diversity and microevolution of this species, although these have to be priory verified in a number of $B$. flabellifer populations. Indeed, further verification of these markers would provide an insight for establishing breeding and conservation programs for this palm species. Because the complete genome sequences of other plants in genus Borassus are not yet available, we were able to describe the evolutionary relationship among the members of Borasseae tribe, but not within the genus. Further analysis at the genus level will provide insight into recent evolutionary of palm species.

\section{Additional files}

Additional file 1. A schematic procedure for isolation and purification of the chloroplast from B. flabellifer (a). The procedure is divided into three main steps: leaf sample preparation and disruption, chloroplast isolation and chloroplast purification. A step sucrose gradient for chloroplast purification, before and after ultra-centrifugation (b). A quality assessment of purified cpDNA using EcoRI digestion and agarose gel electrophoresis (c) The left panel represents cpDNA and EcoRI treated cpDNA isolated from chloroplast pellets without sucrose gradient purification, while the right panel represents those that isolated from chloroplast pellets with sucrose gradient purification.

Additional file 2. Table S1. Gene annotation of the B. flabellifer $\mathrm{cp}$ genome. Table S2. Codon usages of the $B$. flabellifer $\mathrm{cp}$ genome. Table S3. Distribution of SSRs in the B. flabellifer cp genome. Table S4. Large repeat sequences in the $B$ flabellifer $\mathrm{cp}$ genome. Table S5. Comparison of the sequence sizes in four cp genomes of the Borassaseae tribe.

\section{Abbreviations}

CP: chloroplast; IGS: intergenic spacer; IR: inverted repeat; ISSR: inter simple sequence repeat; LCS: large single-copy; RAPD: random amplified polymorphic DNA; SSC: small single-copy; SSR: short sequence repeat.

\section{Authors' contributions}

SA and SV conceived and designed the experiments. AS, PW and SV performed the experiments, analyzed the data and wrote the manuscript. AS prepared the figures and tables. SA and SV corrected and proofread the manuscript. All authors read and approved the final manuscript.

\section{Author details \\ ${ }^{1}$ Center for Agricultural Biotechnology, Kasetsart University, Kamphaeng Saen Campus, Nakhon Pathom 73140, Thailand. ${ }^{2}$ Center of Excellence on Agricultural Biotechnology: (AG-BIO/PERDO-CHE), Kasetsart University, 50 Ngarm Wong Wan Road, Chattuchak, Bangkok 10900, Thailand. ${ }^{3}$ Department of Genetics, Faculty of Science, Kasetsart University, 50 Ngarm Wong Wan Road, Chattuchak, Bangkok 10900, Thailand. ${ }^{4}$ Center of Advanced Studies for Tropical Natural Resources, Kasetsart University, 50 Ngam Wong Wan, Chattuchak, Bangkok 10900, Thailand. ${ }^{5}$ Special Research Unit in Microal- gal Molecular Genetics and Functional Genomics (MMGFG), Department of Genetics, Faculty of Science, Kasetsart University, 50 Ngarm Wong Wan Road, Chattuchak, Bangkok 10900, Thailand. ${ }^{6}$ School of Science, Mae Fah Luang University, Chiang-Rai 57100, Thailand.}

\section{Acknowledgements}

We thank Dr. Anongpat Suttangkakul for discussion and proofreading.

\section{Competing interests}

The authors declare that they have no competing interests.

\section{Availability of data and materials}

The B. flabellifer complete cp genome sequence is available in GenBank (Accession Number: KP_901247).

\section{Consent to publish}

Not applicable.

\section{Ethics approval and consent to participate}

Not applicable.

\section{Funding}

This work was supported by Kasetsart University Research and Development Institute (KURDI), Faculty of Science Research Fund (SCRF), the National Research Council of Thailand and Thailand Research Fund (TRF-RSA6080031). Arpakorn Sakulsathaporn is supported by the Center of Excellence on Agricultural Biotechnology, Science and Technology Postgraduate Education and Research Development Office, Office of Higher Education Commission, Ministry of Education. (AG-BIO/PERDO-CHE).

\section{Publisher's Note}

Springer Nature remains neutral with regard to jurisdictional claims in published maps and institutional affiliations.

Received: 3 April 2017 Accepted: 8 December 2017

Published online: 16 December 2017

\section{References}

1. Morton JF. Notes on distribution, propagation and products of Borassus palms (Arecaceae). Econ Bot. 1988:2:420-41.

2. Haynes J, McLaughlin J. Edible palms and their uses. Gainesville: University of Florida; 2000

3. Bayton RP, Ouédraogo A, Guinko S. The genus Borassus (Arecaceae) in West Africa, with a description of a new species from Burkina Faso. Bot J Linn Soc. 2006;150:419-27.

4. Dransfield J, Beentje H. The palms of Madagascar. The Royal Botanic Gardens, Kew and the International Palm Society; 1995.

5. Bayton RP, Obunyali C, Ranaivojaona R. A re-examination of Borassus in Madagascar. Palms. 2003;47:206-19.

6. Eagleton GE. Persistent pioneers; Borassus L. and Corypha L. in Malesia. Biodiversitas. 2016;17(2):716-32

7. Hazarika T, Marak S, Mandal D, Upadhyaya K, Nautiyal B, Shukla A. Underutilized and unexploited fruits of Indo-Burma hot spot, Meghalaya, northeast India: ethno-medicinal evaluation, socio-economic importance and conservation strategies. Genet Resour Crop Evol. 2016;63:289-304.

8. Davis TA, Johnson DV. Current utilization and further development of the palmyra palm (Borassus flabellifer L., Arecaceae) in Tamil Nadu State, India. Econ Bot. 1987;41(2):247-66.

9. Ambastha K, Hussain SA, Badola R. Resource dependence and attitudes of local people toward conservation of Kabartal wetland: a case study from the Indo-Gangetic plains. Wetl Ecol and Manag. 2007;15:287-302.

10. George J, Karun A, Manimekalai R, Rajesh M, Remya P. Identification of RAPD markers linked to sex determination in palmyrah (Borassus flabellifer L.). Curr Sci. 2007;93:1075-7.

11. Raju DC, Reji J. Genetic diversity analysis in palmyrah palms using RAPD markers. Int J Pharma Bio Sci. 2015;6:244-50.

12. Ponnuswami V. Genetic diversity in palmyrah genotypes using morphological and molecular markers. Electron J Plant Breed. 2010;1:556-67.

13. Pipatchartlearnwong K, Swatdipong A, Vuttipongchaikij S, Apisitwanich S. Cross-genera transferability of microsatellite loci for Asian Palmyra Palm (Borassus flabellifer L.). HortScience. 2017;52(9):1164-7.

14. Pipatchartlearnwong K, Swatdipong A, Vuttipongchaikij S, Apisitwanich S. Genetic evidence of multiple invasions and a small number of founders of Asian Palmyra palm (Borassus flabellifer) in Thailand. BMC Genet. 2017;18(1):88.

15. Triboush SO, Danilenko NG, Davydenko OG. A method for isolation of chloroplast DNA and mitochondrial DNA from sunflower. Plant Mol Biol Report. 1998;16(2):183. 
16. Sandbrink JM, Vellekoop P, Van Ham RJHC, Van Brederode J. A method for evolutionary studies on RFLP of chloroplast DNA, applicable to a range of plant species. Biochem Syst Ecol. 1989;17(1):45-9.

17. Andrews S. 2010. FastQC: a quality control tool for high throughput sequence data. http://www.bioinformatics.babraham.ac.uk/projects/ fastqc/. Accessed 27 Dec 2013.

18. Bolger AM, Lohse M, Usadel B. Trimmomatic: a flexible trimmer for Illumina sequence data. Bioinformatics. 2014;30:2114-20.

19. Huang YY, Matzke AJ, Matzke M. Complete sequence and comparative analysis of the chloroplast genome of coconut palm (Cocos nucifera). PLOS ONE. 2013;8:e74736.

20. Conant GC, Wolfe KH. GenomeVx: simple web-based creation of editable circular chromosome maps. Bioinformatics. 2008;24(6):861-2.

21. Wyman SK, Jansen RK, Boore JL. Automatic annotation of organellar genomes with DOGMA. Bioinformatics. 2004;20(17):3252-5.

22. Liu C, Shi L, Zhu Y, Chen H, Zhang J, Lin X, Guan X. CpGAVAS, an integrated web server for the annotation, visualization, analysis, and GenBank submission of completely sequenced chloroplast genome sequences. BMC Genomics. 2012;13(1):715.

23. Yang M, Zhang X, Liu G, Yin Y, Chen K, Yun Q, Zhao D, Al-Mssallem IS, Yu J. The complete chloroplast genome sequence of date palm (Phoenix dactylifera L.). PLoS ONE. 2010;5:e12762.

24. Schattner P, Brooks AN, Lowe TM. The tRNAscan-SE, snoscan and snoGPS web servers for the detection of tRNAs and snoRNAs. Nucleic Acids Res. 2005;33(suppl 2):686-9.
25. Kurtz S, Choudhuri JV, Ohlebusch E, Schleiermacher C, Stoye J, Giegerich R. REPuter: the manifold applications of repeat analysis on a genomic scale. Nucleic Acids Res. 2001;29(22):4633-42.

26. Wang $X$, Lu P, Luo Z. GMATo: a novel tool for the identification and analysis of microsatellites in large genomes. Bioinformation. 2013;9(10):541-4.

27. Barrett CF, Baker WJ, Comer JR, Conran JG, Lahmeyer SC, LeebensMack JH, Li J, Lim GS, Mayfield-Jones DR, Perez L. Plastid genomes reveal support for deep phylogenetic relationships and extensive rate variation among palms and other commelinid monocots. New Phytol. 2016;209:855-70.

28. Frazer KA, Pachter L, Poliakov A, Rubin EM, Dubchak I. VISTA: computational tools for comparative genomics. Nucleic Acids Res. 2004;32(suppl 2):273-9.

29. Silvestro D, Michalak I. raxmIGUI: a graphical front-end for RAxML. Org Divers Evol. 2012;12(4):335-7.

30. Givnish TJ, Ames M, McNeal JR, McKain MR, Steele PR, Graham SW, Pires JC, Stevenson DW, Zomlefer WB, Briggs BG, Duvall MR. Assembling the tree of the monocotyledons: plastome sequence phylogeny and evolution of poales. Ann Mo Bot Gard. 2010;97(4):584-616.

31. Barrett CF, Davis Jl, Leebens-Mack J, Conran JG, Stevenson DW. Plastid genomes and deep relationships among the commelinid monocot angiosperms. Cladistics. 2013;29(1):65-87.

\section{Submit your next manuscript to BioMed Central and we will help you at every step:}

- We accept pre-submission inquiries

- Our selector tool helps you to find the most relevant journal

- We provide round the clock customer support

- Convenient online submission

- Thorough peer review

- Inclusion in PubMed and all major indexing services

- Maximum visibility for your research

Submit your manuscript at www.biomedcentral.com/submit 